\title{
ANALISA PENERAPAN PERANGKAT LUNAK USBN MANDIRI PADA SMAN 14 BANDUNG DENGAN MENGGUNAKAN BALANCED SCORECARD
}

\author{
Ida Suhartini \\ Jurusan Teknik Komputer dan Informatika \\ Politeknik Negeri Bandung \\ ida@jtk.polban.co.id
}

\begin{abstract}
Abstrak
Pendidikan abad 21 adalah pendidikan yang mengarahkan semua elemen pendidikan baik sekolah, siswa, guru, para staff dan teknisi dapat mengikuti arahan yang ada yatiu meliputi 3 dimensi nformasi, komunikasi, dan etika dan pengaruh sosial. Hal ini sejalan juga dengan peraturan pemerintah yang mencanangkan agar proses evaluasi belajar siswa sudah emnggunakan konsep USBN mandiri yang berbasis komputer.Kompleksitas pekerjaan pada proses evaluasi/ujian siswa menjadi salah satu dorongan agar institusi pendidikan dapat melakukan efisensi dan efektivitas didalamnya. Perlu adanya dukungan dan kerjasama dari semua pihak agar USBN berbasis komputer ini dapat berjalan dengan semestinya. Pengukuran dengan Balance Scorecard dapat memberikan penilaian dari 4 perspektif yaitu keuangan,pelanggan/pengguna, bisnis internal, pertumbuhan dan pembelajaran
\end{abstract}

Kata kunci : Balanced, scorecard, pendidikan, pembelajaran, pengukuran

\begin{abstract}
21 st century education is education that directs all elements of education both schools, students, teachers, staff and technicians can follow the existing directions orphaned in three dimensions of information, communication, and ethics and social influence. This is also in line with the government regulation that proclaims that the learning evaluation process of students has used the concept of independent computer-based USBN.The complexity of the work in the evaluation / student exam process is one of the impetus that educational institutions can carry out efficiency and effectiveness in it. There needs to be support and cooperation from all parties so that this computer-based USBN can run properly. Measurements with Balance Scorecard can provide assessments from 4 perspectives, namely finance, customers / users, internal business, growth and learning
\end{abstract}

Keywords: Balanced, scorecard,education, learning, measurement

\section{Pendahuluan}

Perangkat lunak berperan dalam berbagai fungsi dan dukungan dalam untuk membantu efektivitas dan efisiensi pekerjaan. Dalam dunia pendidikan dalam hal ini kegiatan belajar mengajar, proses ujian memiliki rutinitas dan kompleksitas tersendiri. Kegiatan ujian meliputi pembuatan soal, pengisian jawaban oleh siswa, proses penilaian, pengumuman hasil dan proses remedial.

Dalam pelaksanaannya kegiatan evaluasi siswa membutuhkan waktu yang tidak cepat sementara hasil dari proses ini sangatlah dibutuhkan untuk proses pelaporan kepada siswa dan orangtua/wali.

Kompleksitas pekerjaan menjadi pertimbangan dalam memutuskan perlunya dukungan perangkat lunak sehingga jaminan kehandalan menjadi prioritas. Penerapan ujian berbasis online diharapkan dapat menjadi solusi dalam mengurangi kompleksitas pekerjaan sehingga para guru dapat lebih mengembangkan peran dan tanggung jawabnya.

Berdasarkan Permendikbud No 3 tahun 2017 tentang penilaian hasil belajar oleh pemerintah dan penilaian hasil pembelajaran oleh satuan pendidikan disebutkan ada 3 jenis ujian yang harus ditempuh 
oleh peserta didik agar lulus dari satuan pendidikan, yaitu Ujian Nasional (UN), Ujian berstandar Nasional (USBN) dan ujian sekolah (UN). Mengacu pada pasal 9 Permendikbud no 3 tahun 2017 pemerintah mendorong agar seluruh pelaksanaan UN dilakukan dengan model UNBK.

Dengan memperhatikan kompleksitas pekerjaan dan juga peraturan pemerintah, maka pihak sekoah SMAN 14 Bandung mulai mengadakan USBN mandiri berbasis komputer

\section{Kajian Pustaka}

USBN berasal dari kata ujian sekolah berbasis Nasional, USBN merupakan pengganti UN 2017 yang nantinya akan dihilangkan dan digantikan dengan ujian baru. Kementrian pendidikan dan kebudayaan telah menyiapkan ujian sekolah berbasis Nasional (USBN). Dalam konsep USBN, jenis soal akan terdiri dari pilihan ganda dan essai. Jumlah pilihan ganda akan dikurangi, tak seperti UN yang seluruhnya merupakan pilihan ganda. Hal tersebut perlu dilakukan untuk mendeteksi kemampuan berpikir kritis mahasiswa. USBN nantinya bisa dilaksanakan tanpa kertas atau paperless, sehingga dapat menghemat anggaran, dan mencakup seluruh mata pelajaran dan akan memasukan konten lokal maupun titipan nasional.

\subsection{Profil SMUN 14 Bandung}

Sekolah Negeri 14 Bandung merupakan salah satu sekolah favorit yang berada di kota Bandung dengan visi dan misi sebagai berikut :

Visi

Terwujud sumber daya manusia yang berakhlak mulia, cerdas, dan produktif, serta berbudaya lingkungan.

1. Berakhlak mulia adalah mereka yang religius, beretika, toleran serta memiliki kecerdasan emosional dan spritual

2. Cerdas adalah mereka yang memiliki keunggulan, kritis, mandiri, kreatif dan inovatif

3. Produktif adalah mereka yang proaktif, partisipatif, apresiasitif, aktualitatif, dan profitable.

4. Berbudaya Lingkungan adalah mereka yang meiliki kepedulian dalam memelihara dan menjaga kelestarian lingkungan berkaitan dengan Kebersihan, Ketertiban, Keindahan, Kenyamanan, Kekeluargaan, Kesehatan, Kerindangan (K7) dilingkungannya.

Misi :

1. Meningkatkan mutu pendidikan sesuai dengan perkembangan kebutuhan masyarakat/stakeholders.

2. Mengembangkan, infrastruktur, dan sarana pendidikan melalui pembangunan, pemeliharaan serta pemanfaatan, infra struktuk dan sarana pendidikan dikembangkan sesuai kebutuhan.

3. Meningkatkan kinerja dan layanan pendidikan secara optimal sesuai dengan tugas pokok dan fungsinya, sehingga tercipta produktivitas dan layanan prima.

4. Meningkatkan profesionalisme tenaga kependidikan sehingga memiliki kompetensi sesuai dengan tugas dan proyeksinya.

5. Mengembangkan manajemen pendidikan melalui pengelohaan pendidikan dengan memanfaatkan sumber daya manusia dan sumber daya lainnya serta partisipasi masyarakat yang dikelola secara efesien dan efektif.

6. Memanfaatkan teknologi informasi dan komunikasi, sehingga tercipta sistem informasi yang cepat, tepat dan akurat.

7. Memelihara dan menjaga kelestarian lingkungan berkaitan dengan kebersihan, ketertiban, keindahan, kenyamanan, kekeluargaan, kesehatan, dan kerindangan(K7).

Analisa Penerapan Perangkat Lunak USBN Mandiri pada SMAN 14 Bandung Dengan mengunakan Balanced Scoredcared- (Ida Suhartini ) 
Aplikasi Ujian Sekolah Berbasis Online sudah tersedia dalam versi android disamping versi PC, menggunakan jaringan LAN yang memungkinkan keamanan akses aplikasi dari area yang terbatas. Tujuan di terapkannya ujian berbasis online ini antara lain :

1. Mendukung Program Adiwiyata Mandiri dengan mengalihkan Paper Based Test (PBT) ke Computer Based Test (CBT)

2. Meningkatkan mutu, fleksibilitas dan kehandalan Penilaian Akhir Semester (PAS).

3. Meningkatkan efektifitas, efisiensi dan integritas Penilaian Akhir Semester (PAS)

4. Hasil yang lebih cepat dan detail kepada siswa, orangtua dan sekolah.

Dengan kata lain, penerapan ujian berbasis online ini juga mempersiapkan para siswa untuk dapat menghadapi UN yang sudah mengarah ke ujian berbasis komputer. Aplikasi juga dibuat serupa mungkin dengan aplikasi UN berbasis komputerisasi.

Berikut tampilan menu beranda pada aplikasi USBN SMAN 14 Bandung:

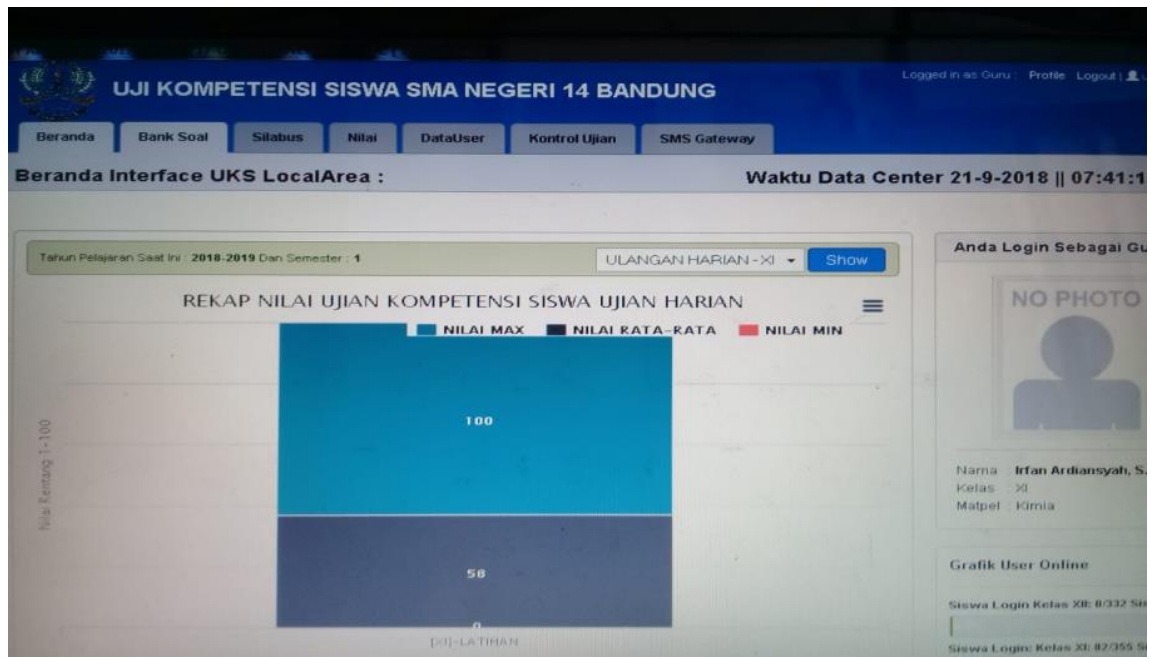

Gambar 1 Tampilan Menu Utama untuk Guru

\section{Metode Penelitian}

\subsection{Pengumpulan Data}

Untuk mendukung memperoleh data yang dibutuhkan guna mendukung penelitian ini teknik pengumpulan data yang digunakan dengan cara metode survey, yaitu merupakan suatu metode pengumpulan data primer yang memerlukan adanya komunikasi antara peneliti dan responden. Adapun salah satu cara pengumpulan data dalam metode survey yaitu teknik kuesioner.

\subsubsection{Wawancara}

Pengumpulan informasi responden didapatkan dari pengguna aplikasi yaitu pihak panitia ujian. Adapun panitia ujian terdiri dari guru yang bertugas sebagai koordinator ujian yang memastikan pengumpulan soal beserta jawaban soal, dan juga TU serta teknisi yang bertugas untuk menyiapkan perangkat teknologi yang diperlukan. Bentuk pengambilan data melalui teknik wawancara dan observasi. Kegiatan ini dilakukan pada saat pelaksanaan ujian dan setelah kegiatan ujian di sekolah.

Beberapa informasi yang didapatkan adalah perbandingan pelaksanaan ujian berbasis online dengan konvensional, arahan dari pihak terkait akan panduan melaksanakan ujian berbasis online serta dan persiapan yang dilakukan untuk melaksanakan ujian. 


\subsubsection{Penyebaran Kuisioner}

Pengumpulan data melalui kuisioner ditujukan untuk pengguna aplikasi dari kalangan siswa dan guru. Responden dapat mengisi melalu platform android maupun desktop dengan link http://bit.ly/KuisionerUASBN_Guru untuk responden gur dan link http://bit.ly/kuisionerUASBN_siswa untuk responden siswa Adapun bentuk kuisioner sebagai berikut :

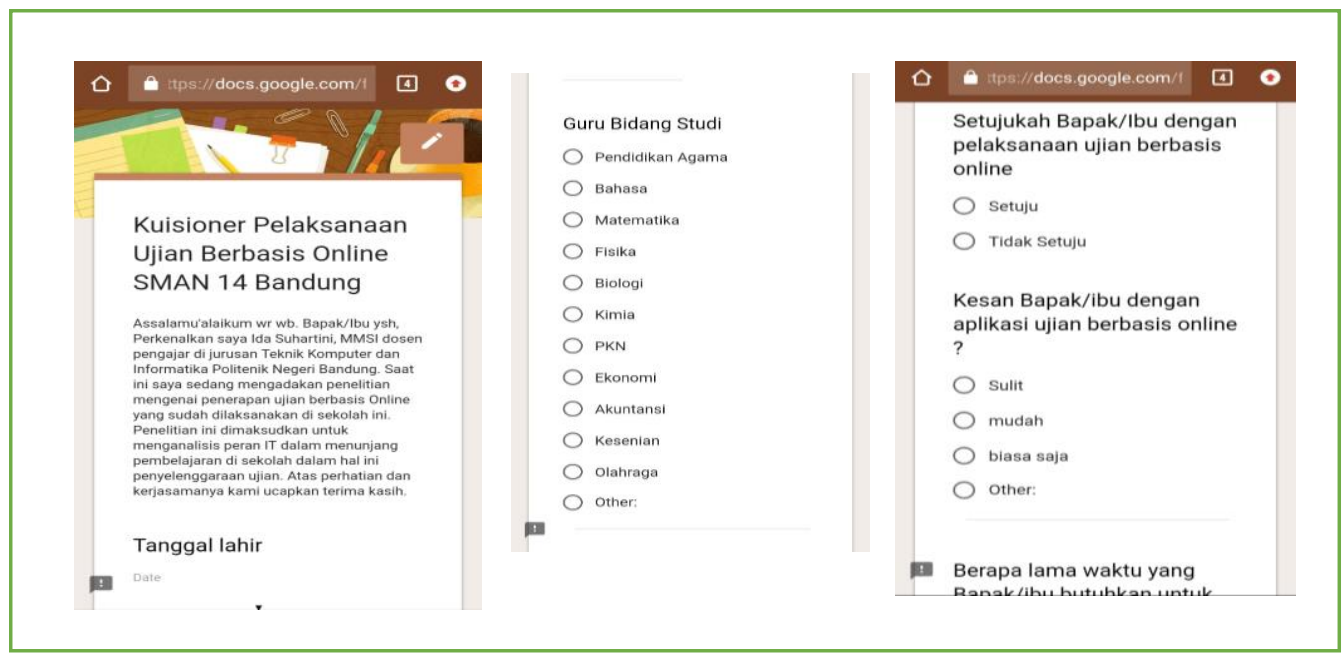

\section{Gambar 2 Kuisioner Responden}

\subsection{Pengukuran menggunakan Balance Scorecard}

Pengukuran untuk menganalisis pelaksanaan penilaian siswa berbasis onlilne menggunakan metode Balance Scorecard yang memiliki model análisis sebagai berikut :

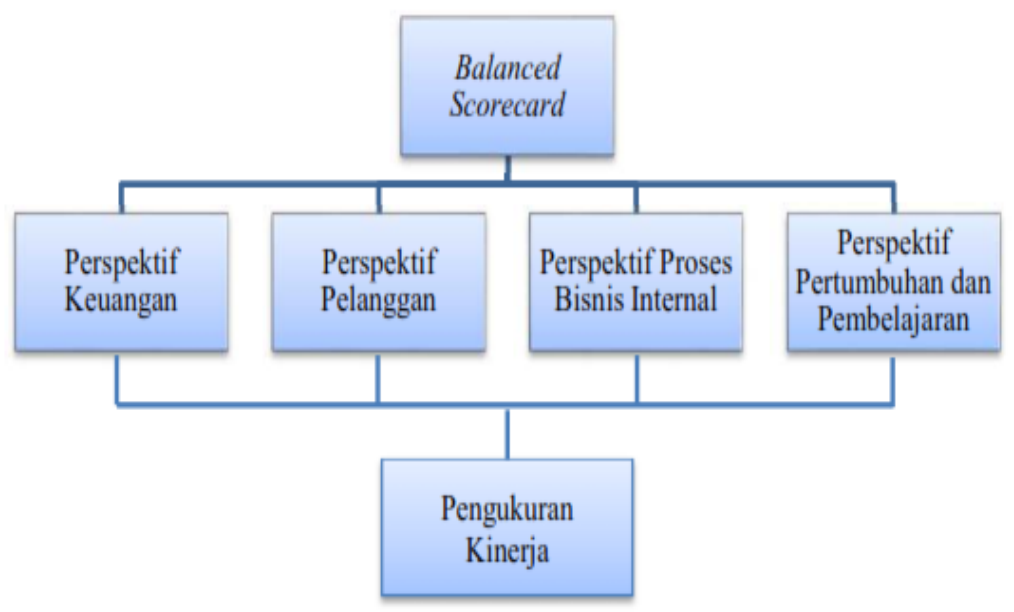

Gambar 3 Model Analisis Penelitian 
Model análisis penelitian dilakukan melalui 4 perspektif antara lain perspektif keuangan, menyusun perbandingan anggaran keuangan sekolah antara penyelenggaraan ujian dengan sistema konvensional dengan ujian yang berbasis online, perspektif pelanggan adalah menilai bagaimana pihak pengguna baik guru maupun siswa serta pihak panitia yang didalamnya ada guru serta teknisi, perspektif bisnis internal meng análisis bagaimana pihak sekolah berupaya untuk melakukan inovasi dalam pelayanan, perspektif pertumbuhan dan pembelajaran, menganalisis bagaimana keberhasilan pihak sekolah dapat mendorong peningkatan kreativitas para guru dalam proses pembelajaran dengan menggunakan teknologi informasi.

\section{Hasil dan Pembahasan}

1.1 Pengambilan Data Responden

\subsubsection{Responden Siswa}

Pengambilan data responden dari siswa dalam penelitian ini sebanyak 59 orang dengan hasil sebagai berikut :

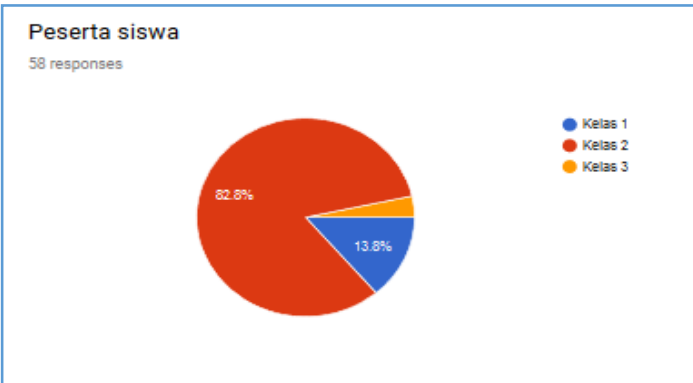

Gambar 4 Grafik Responden Kalangan Siswa dan Pendapat Siswa akan Penyelenggaraan Ujian

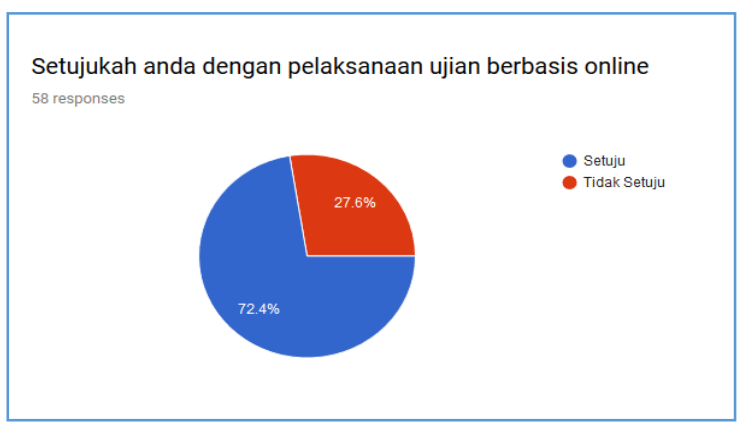

Gambar 5 Grafik Responden Kalangan Siswa dan Pendapat Siswa akan Penyelenggaraan Ujian

Online 
Jumlah peserta responden terbanyak dari kelas 2 yaitu 82,8\% dan paling sedikit dari kelas 3 yaitu 3,4\%.

Dari grafik diatas menyatakan masih ada $27,6 \%$ yang menyatakan ketidak setujuannya dengan pelaksanaan ujian berbasis online meskipun responden sudah terbiasa menggunakan perangkat teknologi informasi. Adapun alasan yang dikemukakan dapat terlihat dari grafik berikut.

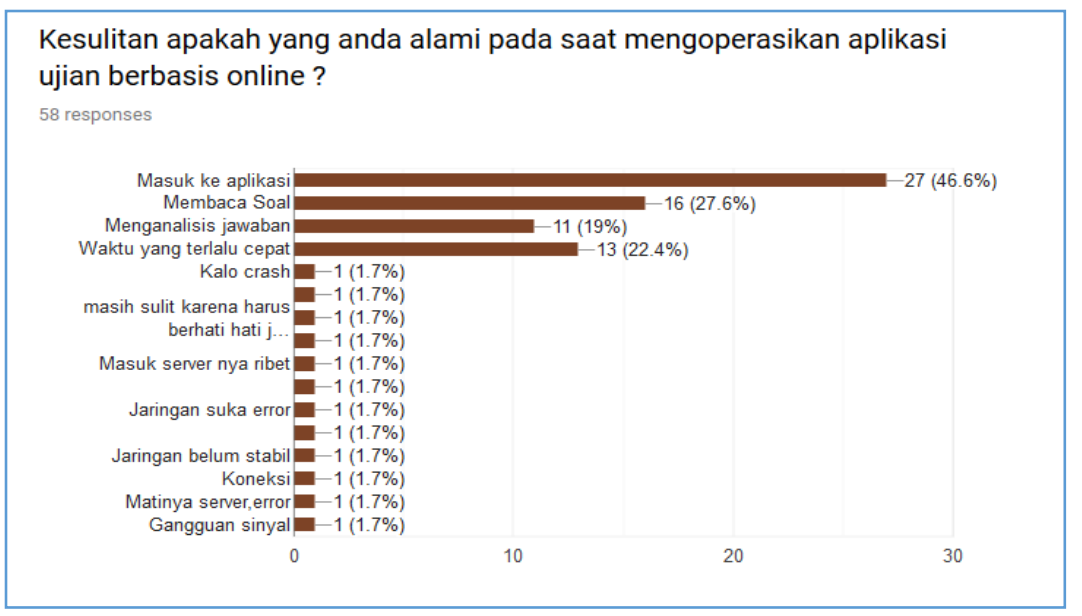

\section{Gambar 6. Grafik Pendapat Siswa aan kesulitan menggunakan Aplikasi}

Kesulitan yang paling dominan dialami oleh peserta adalah pada saat awal penggunaan aplikasi. Hal ini diasumsikan bahwa pada saat pelaksanaan para peserta mengalami kendala untuk login. Sehingga sebagian siswa masih ada yang menyatakan ujian konvensional masih lebih baik dibandingkan dengan ujian berbasis online.

\subsubsection{Responden Guru}

Dari responden guru, jumlah responden cukup mewakili dari keseluruhan guru bidang studi yang menyelenggarakan ujian berbasis online.

\subsection{PENELITIAN TERDAHULU}

\section{Computer Attitude}

Computer attitude merupakan sikap reaksi atau penilaian seseorang terhadap komputer. Sikap kesenangan atau ketidaksenangan terhadap komputer. Sikap tidak senang dalam diri seseorang untuk berkomputer, membuat dirinya tidak memiliki semangat untuk belajar komputer. Sebaliknya, sikap senang terhadap komputer akan membangkitkan semangatnya dalam belajar berkomputer (Kumara, 2014). Dengan kata lain secara umum attitude menunjukkan perasaaan kesenangan atau ketidaksenangan seseorang terhadap obyek stimulus dalam Kuntardi, D. B (2004). Penelitian yang dilakukan Morrison dalam Budiono (2004) terhadap orang-orang Australia menunjukkan bahwa sikap orang Australia terhadap komputer berbeda dengan sikap orang Amerika, yaitu menganggap komputer sebagai alat yang sangat berguna dan sebagai mesin pemikir yang sangat mengagumkan.

\section{Optimism}

Dalam Perdana (2010), optimisme (optimism) seseorang akan muncul atas kehadiran komputer, mereka merasa bahwa kehadiran komputer mampu meringankan setiap pekerjaan dan memberikan berbagai manfaat. Mereka percaya bahwa dengan adanya komputer dalam kehidupan manusia maka efisiensi dalam setiap pekerjaan akan dapat dicapai, semua pekerjaan yang biasanya dilakukan oleh manusia dapat digantikan oleh komputer yang mampu memberikan hasil yang lebih cepat dan akurat.

Analisa Penerapan Perangkat Lunak USBN Mandiri pada SMAN 14 Bandung Dengan mengunakan Balanced Scoredcared- (Ida Suhartini) 
Menurut Burkett et al (2001) computer optimism merupakan sikap positif yang ditunjukkan seseorang dalam berkomputer. Sikap optimis tersebut dapat membantu seseorang untuk melakukan pekerjaan dengan lebih cepat dan lebih baik.

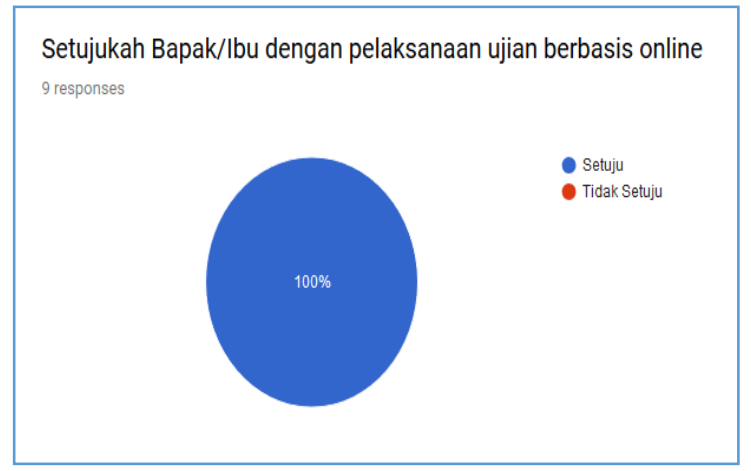

Gambar 7 Grafik Respon Guru terhadap Penyelenggaraan

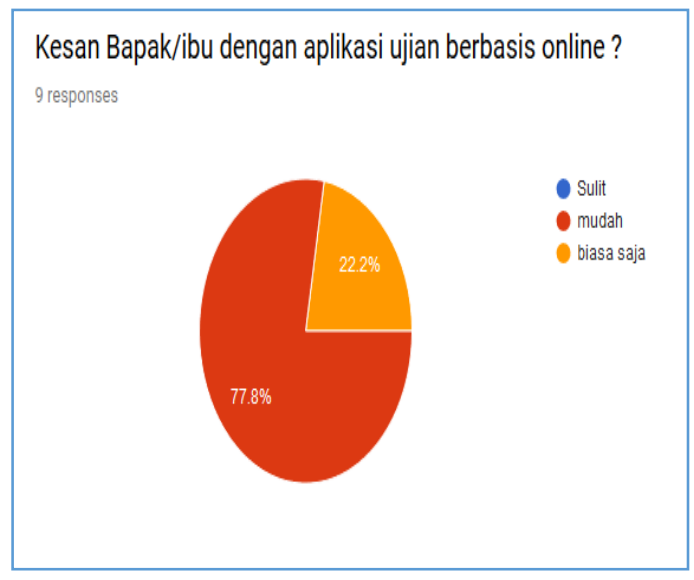

Gambar 8 Grafik Respon Guru terhadap Penyelenggaraan Ujian Online dan Kesannya

Bahwa dari grafik tersebut responden ( guru ) dapat menggunakan aplikasi ujian dengan tingkat yang berbeda namun tidak ada yang menyebutkan kesulitan.Adapun yang masih menjadi kendala dapat dilihat sebagai berikut 


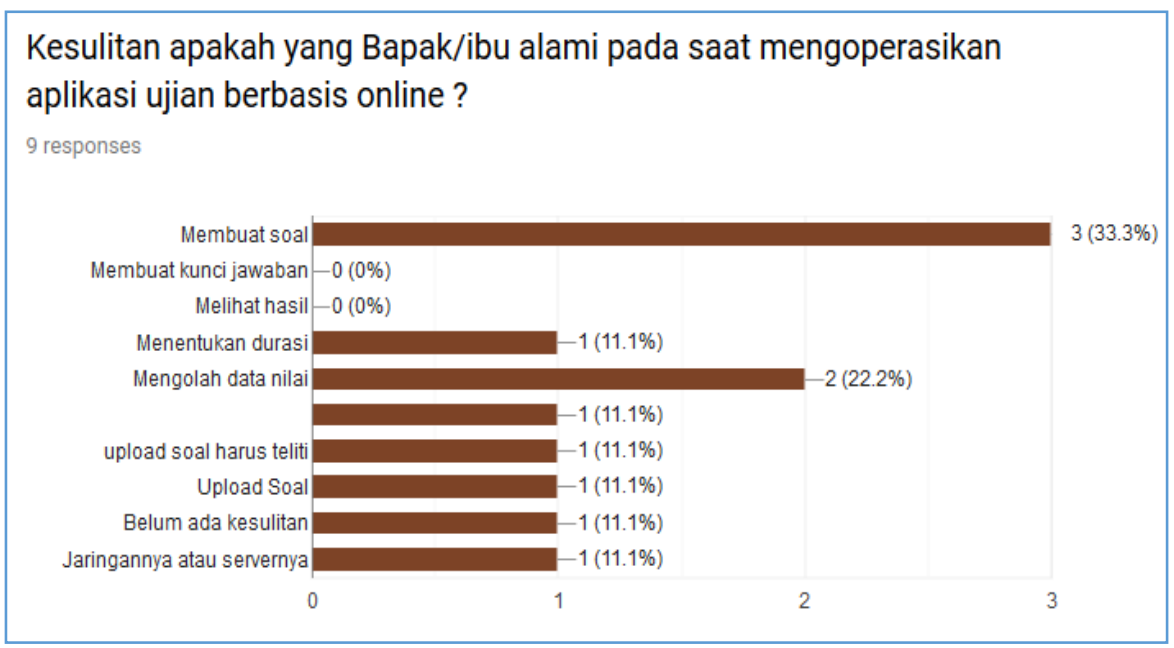

Gambar 9 Grafik Kendala Responden ( Guru )

Pembuatan soal masih menjadi kendala dan menjadi tahapan yang palling lama menurut para responden mengingat memang tidak mudah untuk menyusun soal dengan tepat. Siswa akan mendapatkan soal dengan variasi yang berbeda sehingga sulit jika akan melakukan kecurangan

\subsection{Pengukuran Balance Scorecard}

\subsubsection{Perspektif Keuangan}

Pengukutan dari perpsektif keuangan dalam studi kasus penelitian ini dengan membandingkan anggaran yang dikeluarkan dengan sisem ujian konvensional ( berbasis kertas ) dengan sistem berbasis komputerisasi.

Adapun Pengeluaran Sekolah dengan sistem ujian konvensional antara lain :

1. Pencetakkan soal

Rp 150 x 16 Mapel x 1015 siswa = Rp 2.436.000

2. Pencetakkan lembar jawaban

1015 siswa $x$ Rp $150=\operatorname{Rp} 152.250$

3. Biaya koreksi

Rp 500 x 16 Mapel x 1015 siswa = Rp 40.600 .000

daan ATK lain ( amplop soal @ruangan )

28 ruangan x 2 amplopx 6 hari $x 3$ sesi $x$ Rp $2000=\operatorname{Rp} 2.160 .000$

Total biaya penyelenggaraan ujian kertas ( konvensional ) Rp 45.348.250

Dengan penyelenggaraan Aplikasi USBN, biaya pencetakkan soal, koreksi jawaban siswa, serta pencetakkan lembar jawaban dapat dihilangkan.

Sebagai tambahan, aplikasi dapat di unduh di fitur "playstore" pada Handphone masing - masing peserta sehingga perangkat ujian ( client ) dapat menggunakan resources dari peserta. 


\subsubsection{Perspektif Pelanggan}

Pelanggan dalam hal ini adalah para pengguna aplikasi ujian online yaitu guru dan siswa. Pada grafik diatas responden guru dan siswa memberikan respon yang tidak jauh berbeda. Para guru setuju dengan pelaksanaan ujian online dengan cukup signifikan mengurangi beban pada saat koreksi dan pengolahan nilai, sedangkan pada siswa, cenderung menerima dengan catatan " kestabilan" koneksi internet sehingga tidak banyak menghambat ujian.

\subsubsection{Perspektif Bisnis Internal}

Bahwa dengan penerapan ujian berbasis online ini sangat mendorong para guru terutama untuk dapat melakukan kreativitas dalam proses pendidikan ke anak didiknya. Waktu yang digunakan untuk mengoreksi dan mengolah nilai dapat diarahkan untuk dapat melakukan pengembangan media pembelajaran lainnya serta memungkinkan untuk lebih banyak untuk dapat berinteraksi dengan para siswanya.

\subsubsection{Perspektif Pertumbuhan dan Pembelajaran}

Peralihan bentuk evaluasi siswa dari sistem ujian konvensional ke sistem ujian terkomputerisasi dan online memberikan perubahan kearah yang positif. Walau dari hasil survey dari sebagian siswa masih memilih sistem ujian konvensional namun masih dapat dimaklumi mengingat kendala pada penerapan sistem ujian online bukan pada aplikasi, melainkan dari ketersediaan support jaringan internet. Hal ini masih dapat diantisipasi dengan baik oleh pihak panitia. Tidak berjalannya aplikasi di beberapa perangkat telepon siswa juga masih dapat teratasi dengan memindahkan peserta ujian ke lab komputer sehingga ujian tetap bisa berjalan.

\section{Kesimpulan dan Saran}

Kesimpulan dari penelitian ini sebagai berikut :

1. Penyelenggaraan USBN mandiri berbasis komputer dapat memberikan proses ujian dengan lebih cepat dan efisien

2. Hasil belajar siswa dapat dengan langsung diketahui, sistem ujian yang aman menjadi tercapainya target yaitu ujian yang aman dan terkendali

3. Proses pembuatan soal yang masih menjadi kendala dapat disolusikan dengan memberikan pelatihan lanjutan untuk para guru

4. Biaya yang operasional pada sistem ujian berbasis kertas (konvensional) dapat ditekan dengan penyelenggaraan ujian berbasis komputer

5. Peserta ujian akan menjadi lebih siap dalam menghadapi UN berbasis komputer, mengingat aplikasi USBN mandiri dibuat sama seperti UN berbasis komputer

Maka dengan pengukuran Balance Scorecard dapat terlihat bahwa sistem USBN dapat meningkatkan produktivitas dari semua pihak baik sekolah, guru maupun para siswa serta pihak terkait lainnya.

Adapun saran dari hasil penelilitian ini adalah :

Sistem ujian berbasis komputer (online) dapat dengan lebih baik pelaksanaannya dengan mulai membiasakan para guru dan siswa menggunakan aplikasi sejenis untuk aktivitas pembelajaran. Para siswa juga harus terus diedukasi agar dapat mengikuti dengan sebaik-baiknya. Sarana penunjang laiinya seperti kemampuan server dan stabilitas jaringan masih perlu terus ditingkatlkan dan menjadi perhatian utama. 


\section{Daftar Pustaka}

[1]. Panduan Penilaian oleh Pendidik dan Satuan Pendidikan SMA

[2]. Hery, S.E., M.Si., CRP., RSA., CFRM.(2017). Balanced Scorecard for Business, Grasindo

[3]. https://unbk.kemdikbud.go.id/persyaratan\#content

[4]. Mahsina (2017), Analisis Penerapan BALANCE SCORECARD, Alat Ukur Penilaian Kinerja Pada

Dinas Pendapatan, Pengelolaan Keuangan dan Aset Kabupaten Sidoarjo,

[5].Panduan Aplikasi UKS 2017 